\title{
Engel Uzunluğunun Karıştırıcı Güç Sayısına Etkisi
}

\author{
İnci AYRANCI*, Gökhan GÖK \\ Orta Doğu Teknik Üniversitesi, Kimya Mühendisliği Bölümü, Ankara \\ (ORCID: 0000-0003-4625-9862) (ORCID: 0000-0001-7420-4047)
}

\begin{abstract}
Öz
Karıştırmalı tanklarda en önemli tasarım parametrelerinden bir tanesi güç tüketimidir. Tasarım, sürecin amacı ve güç tüketiminin birlikte değerlendirilmesi sonucu, en iyi sonucun en düşük güç tüketiminde elde edildiği sistem düzenlemesine göre yapılır. Karıştırmalı tanklarda genel olarak tam engel kullanılmaktadır. Ancak bazı durumlarda daha kısa ve yüzeye yakın veya tankın tabanından belli bir mesafe uzaktan başlayan engellerin kullanılması sürecin amaçları açısından daha uygun olmaktadır. Bazı durumlarda ise hiç engel kullanılmaz. Güç tüketiminin hesaplanması için karıştırıcıya özel güç sayısının bilinmesi gerekmektedir. Literatürde tam engel kullanıldığı zaman karıştırıcıların güç sayıları yaygın olarak verilmiştir. Ancak, farklı tür engeller kullanıldığındaki güç sayıları bilinmemekte ve bu sebeple bu sistemlerin güç tüketimleri tasarım aşamasında hesaplanamamaktadır. Bu çalışmada karıştırmalı bir tankta engel uzunluğunun karıştırıcı güç sayısına etkisi araştırılmıştır. Tam engel, tabandan boşluklu engel, yüzey engeli, yarım engel ve engelsiz tank düzenlerinde eğimli bıçaklı karıştırıcının tork değerleri geniş bir Reynolds sayısı aralığında öllçülmüş ve güç sayıları hesaplanmıştır. En küçük güç sayılarına engelsiz düzende ve sonrasında yüzey engeli ile ulaşılmışıtır.
\end{abstract}

Anahtar kelimeler: Güç sayısı, engel tipi, karıştırmalı tanklar, tork ölçümleri.

\section{The Effect of Length of the Baffle on the Power Number}

\begin{abstract}
One of the most important design parameters for stirred tanks is the power consumption. Design is based on a simultaneous evaluation of process mixing objective and power consumption. The configuration that gives the best process results at minimum power consumption gives the final design. In stirred tanks, often fully baffled tanks are used. In some processes, however, it was shown that shorter, closer to surface, or off-bottom baffles are more suitable in terms of process objectives. Unbaffled tanks are also sometimes used. Impeller specific power number needs to be known in order to calculate power consumption. The power number of various impellers are given in literature for baffled tanks. For different types of baffles, however, no power number information is available in the literature. This means that the power consumption cannot be calculated while designing these tanks. In this study, the effect of length of the baffle on the power number was investigated. Full baffles, offbottom baffles, half baffles, surface baffles and no baffles configurations were used. The torque values of a pitched blade turbine impeller were measured over a wide range of Reynolds numbers, and power numbers were calculated. The minimum power number was observed for the unbaffled tank. This was followed by surface baffles.
\end{abstract}

Keywords: Power number, baffle type, stirred tanks, torque measurements.

\section{Giriș}

Tanklarda karıştırma kimyasal süreçlerde sıklıkla kullanılan temel işlemlerdendir. Kimyasal üretimi, kozmetik, ilaç, boya, polimer üretimi, gıda, mineral, deterjan üretimi ve benzeri birçok sanayide kullanılan bir birimdir. Karıştırmalı tankların tasarımında öncelikli amaç istenilen ürünü elde etmek olmakla birlikte, eğer bu koşul karıştırıcı hızını arttırmaktan geçiyor ise tasarım yapan bir mühendisin güç tüketimini göz önüne alması ve çok yüksek olmamasına dikkat etmesi gerekir. Bunun sebebi

\footnotetext{
*Sorumlu yazar: ayranci@metu.edu.tr

Geliş Tarihi: 28.11.2019, Kabul Tarihi: 07.10.2020
} 
karıştırmalı tanklarda güç tüketiminin karıştırıcı hızının üçüncü kuvveti ile değişmesi ve bu sebeple karıştırıcı hızının artması ile güç tüketiminin çok fazla artmasıdır.

Bir karıştırmalı tankta geometrik özellikler akışı ciddi anlamda etkiler. Karıştırıcı tipi, karıştırma sürecinin amacına göre seçilmelidir. Türbülent sistemde akışın gerçekleştiği tanklarda kullanılan üç tip karıştırıcı vardır: eksenel, radyal ve radyal-eksenel karıştırıcılar [1]. Eksenel karıştırıcılar genel olarak katıların sıvılar içinde süspansiyonu için kullanılır [2]. Bu karıştırıcılar sıvıyı önce tank tabanına yönlendirir. Daha sonra engellerin de yardımıyla akış yukarı yönelir ve katılar süspanse olur. Radyal karıştırıcilar genel olarak sıv1-sıvı sistemlerde veya gaz sıv1 sistemlerde bir sıvıyı bir başka sıvı içerisinde veya bir gazı bir sıvı içerisinde dağıtmakta kullanılır. Radyal-eksenel karıştırıcılar ise bu iki amacın her ikisini de ortalama olarak karşılar. Bu karıştırıcılar ile sıvı/gaz dağılımı ile aynı zamanda tanecik süspansiyonu da sağlanabilir. Bu sebeple ve imalatlarının kolay olması sebebiyle endüstride sıklıkla kullanılan bir karıştırıcı tipidir. Bu çalışmada da bu karıştıııcı tipi kullanılmıştır.

Yukarıdaki paragrafta da belirtildiği üzere karıştırmalı tanklarda engeller akışın yönünü değiştirmek amacıyla kullanılmaktadır. Engellerin varlığında akış yukarı doğru yönlendirilmektedir. Engeller olmadığında ise akış açısal akış tarafından domine edilerek devam etmektedir. Engeller çoğu kimyasal süreç için kullanılmakta ve kullanılması tavsiye edilmektedir [1]. Katı taneciklerin sıvılar içerisinde süspansiyonu engel kullanılması gereken süreçler listesinin başında gelmektedir. Endüstriyel tanklarda engeller tankın içerisine kaynaklanmaktadır. Haliyle üretim aralarında tankın temizlenmesi gerektiğinde engeller çıkarılamamaktadır. $\mathrm{Bu}$, gıda ve ilaç endüstrisi gibi bazı endüstrilerde bir sorun teşkil edebileceğinden bazen süreçler engelsiz tanklar ile yürütülmektedir [3]. Ayrıca kristalizasyonda bazen engellerin varlığı oluşan taneciklere zarar verebileceğinden engelsiz tanklar tercih edilmektedir. Bunların dışında, literatürdeki çeşitli çalışmalar farklı engel tiplerinin bazı süreçler için daha verimli olabileceğini göstermiştir. Örneğin Myers vd. [4] katı taneciklerin sıvılar içinde süspansiyonunda engellerin tank tabanından bir miktar uzak bir mesafeden başlayıp yukarı kadar uzanması durumunda tanecik süspansiyonunun hala gerçekleştiğini, ancak güç tüketiminin \%14 oranında azaldığını göstermiştir. Khazam ve Kresta [5] yüzen taneciklerin sıvının içerisine alınması sürecinde yüzey engellerinin kullanılmasının taneciklerin tank içerisinde daha derine daha kolay inebilmesini sağladığını göstermiş̧ir. $\mathrm{Bu}$ çalışmalar, farklı engel tiplerinin karıştırmalı tanklarda verimli olarak kullanılabileceğini göstermektedir. Ancak, bu tür engellerin kullanılması durumunda güç tüketiminin ne olacağının mevcut literatür bilgisi ile hesaplanması mümkün değildir. Güç tüketimi aşağıdaki eşitlik ile hesaplanır:

$$
P=\rho N_{p} N^{3} D^{5}
$$

Burada P güç tüketimini $(\mathrm{W}), \rho$ sıvının yoğunluğunu $\left(\mathrm{kg} / \mathrm{m}^{3}\right), \mathrm{N}_{\mathrm{p}}$ karıştırıcının güç sayısını, $\mathrm{N}$ karıştırıcı hızını (devir/s) ve D karıştırıcı çapını (m) temsil eder. Burada güç sayısı karıştırıcıya özgü bir değerdir, ancak karıştırıcının tipine ve sayısına olduğu kadar, akış rejimine ve tankın geometrisine de bağlıdır [69]. Laminer rejimde güç sayısı Reynolds sayısı ile ters orantılıdır [10]. Türbülent rejime doğru arttırılan karıştırıcı hızlarında güç sayısı düşüş gösterir ve türbülent rejimde sabit bir değere ulaşır $[11,12$.] Bu durumda bir sistem türbülent rejimde çalışıtırılacak ise ve karıştırıcının güç sayısı biliniyor ise güç tüketimi hesaplanabilir. Ancak literatürde güç sayıları engelli tanklar için verilmiştir $[1,11,13]$. Bu sebeple farklı engel tipleri kullanıldığında güç tüketiminin hesaplanması mümkün değildir. $\mathrm{Bu}$ araştırmanın amacı literatürdeki bu açığı kapatmaktır.

Bu çalışmada radyal-eksenel bir karıştırıcının kullanıldığı bir karıştırmalı tankta dört farklı engel tipinde ve bir de engelsiz düzende güç sayısının artan Reynolds sayıları ile nasıl değiştiği incelenmiş ve bu karıştırıcı tipinin bu farklı düzenlerdeki güç sayıları rapor edilmiştir. Böylelikle bu karıştırıcı tipinin kullanılacağı bir sistem için, sistem kurulmadan tasarım aşamasında, güç tüketimi hesabı bu beş düzen arasından istenilen herhangi biri için yapılabilecektir.

\section{Materyal ve Metot}

Deneyler 0,24 m iç çapında $(\mathrm{T})$ bir pleksi tankta gerçekleştirilmiştir. Çapı tank çapının yarısı $(\mathrm{D}=\mathrm{T} / 2)$ olan $45^{\circ}$ eğimli bıçaklı bir karıştırıcı (PBT) kullanılmıştır. Karıştırıcının fotoğrafi Şekil 1'de, boyutları Tablo 1'de verilmiştir. Karıştırıcı, bütün deneylerde tank tabanından, tank çapının üçte biri $(\mathrm{C}=\mathrm{T} / 3)$ kadar bir mesafeye yerleştirilmiştir. Bütün deneylerde sıvı faz olarak damıtılmış su kullanılmıştır. Sıvı 
yüksekliğinin tank çapına eşit geldiği noktaya $(\mathrm{H}=\mathrm{T})$ pleksi bir kapak yerleştirilmiş ve sonrasında bu kapağın üzeri bir miktar su ile doldurulmuştur. Bunun sebebi ölçümlerin sıvı yüksekliğinin tank çapına eşit olduğu bir sistem için yapılmak istenmesi, ancak içeri hava girişinin engellenmesidir. Tork ölçümleri literatürde de bu şekilde yapılmaktadır [13]. Metnin geri kalanında sıvı yüksekliği veya sıvı yüzeyi ile kastedilen, tankın çapı kadar olan $(\mathrm{H}=\mathrm{T})$ yüksekliktir.

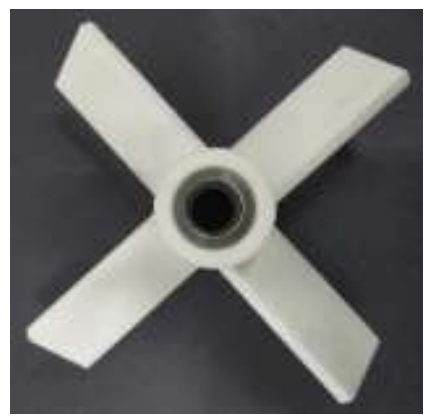

Şekil 1. PBT karıştırıcının fotoğrafi

Tablo 1. Deneylerde kullanılan PBT karıştırıcının boyutları

\begin{tabular}{|c|c|}
\hline Karıştırıcı kısmı & Değeri (m) \\
\hline Çap1 & 0,12 \\
\hline Bıçak uzunluğu & 0,0485 \\
\hline Bıçak genişliği & 0,024 \\
\hline Bıçak kalınlığı & 0,004 \\
\hline Orta yüzük genişliği & 0,029 \\
\hline Orta yüzük iç çapı & 0,014 \\
\hline Orta yüzük yüksekliği & 0,030 \\
\hline
\end{tabular}

Deneylerde dört tip engel kullanılmıştır. Ayrıca engelsiz düzende de ölçümler gerçekleştirilmiştir. Deneylerde kullanılan düzenekler Şekil 2'de gösterilmiştir. Dört engel tipi şu şekilde isimlendirilmiştir: tam engel, tabandan boşluklu engel, yarım engel ve yüzey engeli. Her bir engel tipinde, standart engellerde olduğu gibi, dört adet karşıllklı bacak (engel) bulunmaktadır. Her bir engel tank çapının onda biri genişliktedir (T/10). Tam engelde engeller bütün sıvı yüksekliğini kaplayacak yüksekliktedir. Tabandan boşluklu engel tank tabanından, tankın çapının dörtte biri kadar bir boşluk kalıncaya kadar uzanmaktadır. Yarım engel sıvı yüzeyinden tankın çapının yarısı kadar aşağı uzanmaktadır. Yüzey engeli ise sıvı yüzeyinden tankın çapının dörtte biri kadar aşağı uzanmaktadır.

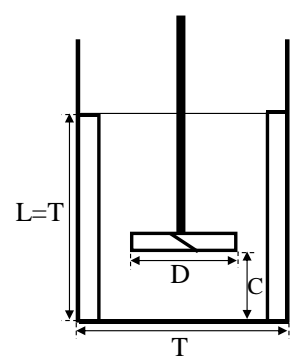

a.

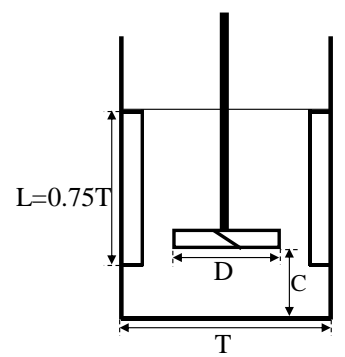

b.

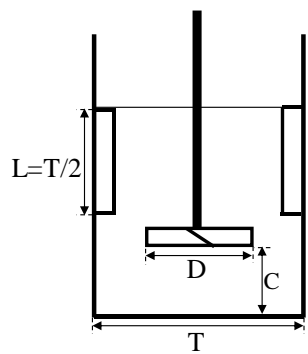

c.

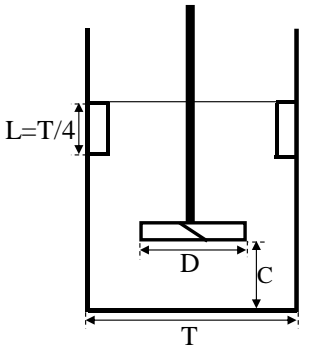

d.

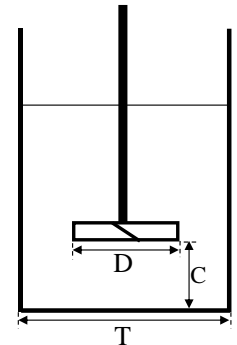

e.

Şekil 2. Tank ve engel geometriler a) tam engel, b) tabandan boşluklu engel, c) yarım engel, d) yüzey engeli, e) engelsiz 
Tork ölçümlerinde ETH DRBK serisi dinamik, 0-10 Nm ölçüm aralıklı tork sensörü kullanılmıştır. Düzenek kurulduktan sonra karıştırıcı hızı 20 devir/dk'dan itibaren 20 devir/dk' lik artışlarla 1100 devir/dk'ya kadar arttırılmıştır. Her bir karıştırıcı hızında öncelikle 10 saniye -1 dakika arası sistemin yatışkın duruma gelmesi beklenmiş, sonrasında da 1 dakika boyunca tork değerleri kaydedilmiştir. Daha sonra hız 20 devir/dk arttırılarak aynı süreç tekrarlanmıştır. Buradaki hız değerleri hem geçiş rejimi hem de türbülent rejimi kapsayacak şekilde seçilmiştir. Reynolds sayısı $\left(\rho N D^{2} / \mu\right)$ cinsinden bu aralık 4780-262946'dır. Karıştırmalı tanklarda $\mathrm{Re}<10$ laminer rejimi, $\mathrm{Re}>20000$ türbülent rejimi temsil etmektedir. $10<\operatorname{Re}<20000$ aralığ 1 geçiş rejimi olarak bilinir. Son zamanlarda yapılan çalışmalarda tankın içerisinde her noktada türbülent rejim olması için Reynolds sayısının 300000'in üzerinde olması gerektiği rapor edilmiştir [14]. Reynolds sayısı 20000'in üzerinde olduğunda güç sayısı artan Reynolds sayısı ile değişmez, sabit kalır. Bu sebeple bu çalışmadaki karıştırıcı hızı seçimleri geçiş rejimi ve tam türbülent rejimi kapsayan Reynolds sayıları elde edilecek şekilde yapılmıştır.

Deneylerde ilk olarak sadece şaft ile ölçümler alınmıştır. Sonra aynı deney şaftın ucuna karıştırıcının takılması ile gerçekleştirilmiştir. Sonuçta elde edilen karıştırıcılı tork değerinden karıştırıcısız şaft tork değeri çıkarılmış ve güç sayısı hesaplamalarında bu tork değeri kullanılmıştır. Güç sayısının hesaplanması için tork ölçümleri literatürde de bu yöntemle yapılmaktadır [13]. Hesaplanan bu fark tork değerinden aşağıdaki eşitlik kullanılarak güç tüketimi hesaplanır:

$$
\mathrm{T}=\frac{\mathrm{P}}{2 \pi \mathrm{N}}
$$

Burada T torku (Nm), P güç tüketimini (W) ve N karıştırıcı hızını (devir/s) temsil etmektedir. Bu şekilde güç tüketimi hesaplandıktan sonra Eşitlik 1 kullanılarak güç sayısı hesaplanır.

\section{Bulgular ve Tartışma}

Bu bölümde ilk olarak her bir engel tipinde ve engelsiz düzende, test edilen bütün karıştırıcı hızları için ölçülen tork değerleri verilmiştir. Sonra, bu tork değerleri kullanılarak güç sayıları hesaplanmış ve verilmiştir. En son olarak, bütün engel tipleri ve engelsiz düzen için tam türbülent güç sayıları raporlanmış ve bir örnek üzerinden bu güç sayıları kullanılarak nasıl karıştırmalı tank tasarımı yapılacağı anlatılmıştır. Şekil 3'te torkun karıştırıcı hızı ile değişimi gösterilmiştir. Tork değerleri tam engelli tanklarda en yüksek, engelsiz tanklarda ise en düşük çıkmıştır. Diğer üç düzende, tabandan boşluklu, yarım ve yüzey engellerinde, ise birbirine yakın ve tam engelli ve engelsiz düzenlerin arasında değerler elde edilmiştir.

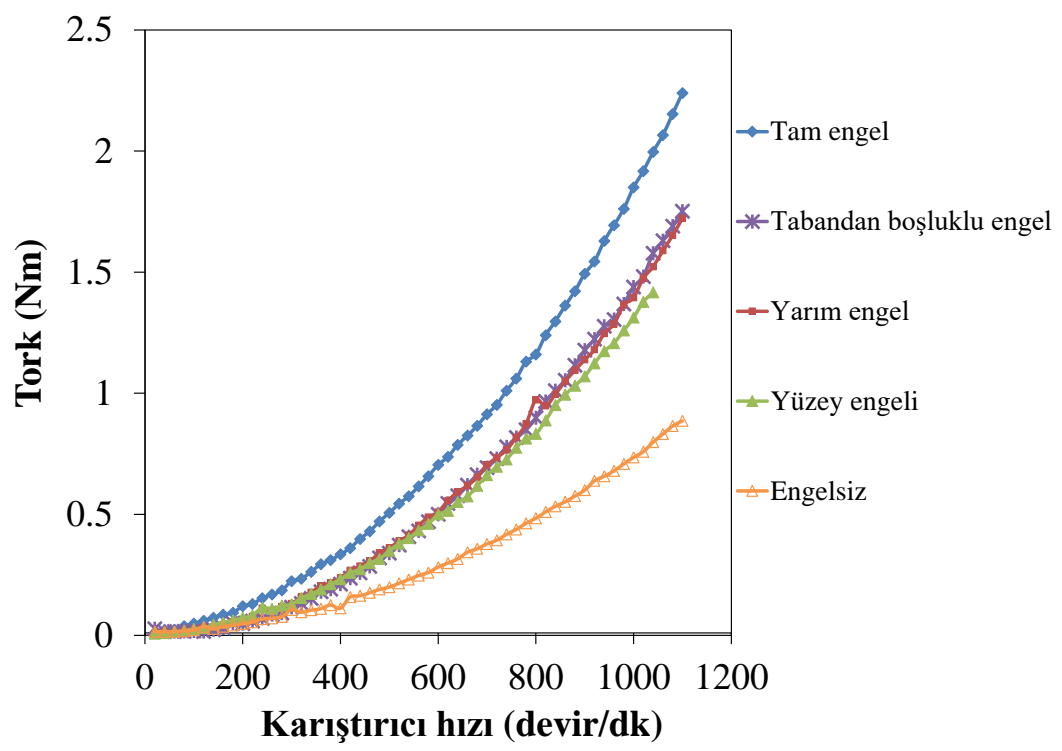

Şekil 3. Tüm engel düzenlerinde karıştırıcı hızı ile değişen tork değerleri 
Şekil 3'te elde edilen tork değerlerinden Eşitlik 2 kullanılarak güç tüketimleri hesaplanmıştır. Daha sonra Eşitlik 1 kullanılarak güç sayıları hesaplanmıştır. Sonuçlar Şekil 4 ve Şekil 5'te gösterilmektedir. Şekil 4'te tam engellerin olduğu durumda değişen Reynolds sayılarına karşılık gelen güç sayıları verilmiştir. Bu engel düzeni, literatürde rapor edilen güç sayılarının ölçüldüğü standart düzendir. Güç sayıs1-Reynolds sayısı eğrisi genel şekil ve eğilim olarak literatür ile bire bir uyumludur [1]. Düşük Reynolds sayılarında yüksek olan güç sayısı, Reynolds sayısının artması ile azalır ve türbülent rejimde sabit bir değere ulaşır. Geçiş rejiminde güç sayısındaki azalan trend literatür ile uyumludur. Burada tam türbülent rejimde, yani Reynolds sayısının 200 000'den büyük olduğu durumda sabit olan güç sayısı 1.68'dir. PBT karıştırıcı için literatürde verilen güç sayısı değeri 1.27'dir [1]. Bu çalışmada elde edilen ve literatürde verilen değer arasında bir miktar fark bulunmaktadır, ancak karıştırıcının bıçak uzunluğu, genişliği ve benzeri geometrik özelliklerinin karıştırıcının güç sayısını etkileyebildiği bilinmektedir [11]. Elde edilen değer ile literatür değeri, geometrik farklar göz önüne alındığında uyumludur.

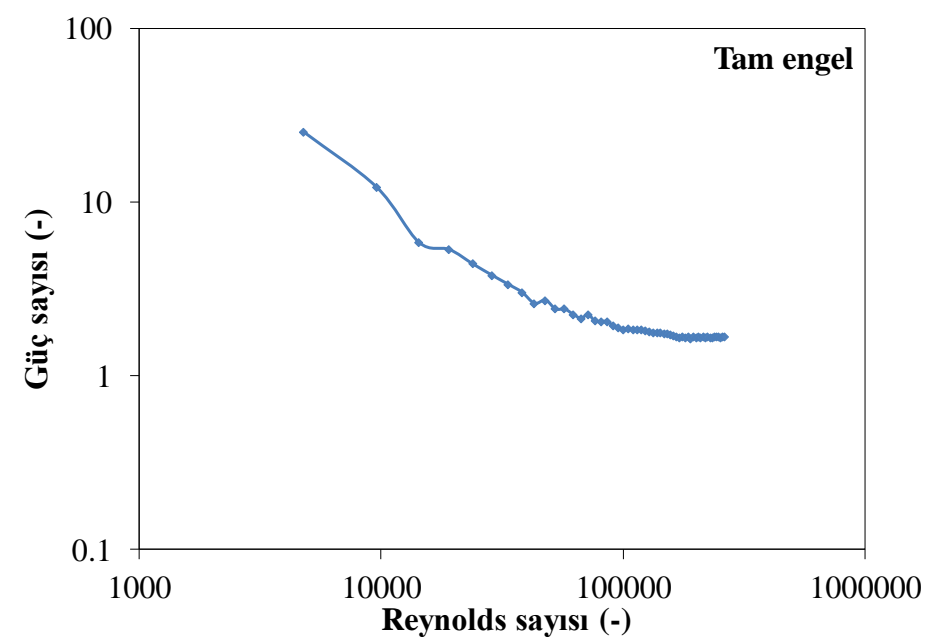

Şekil 4. Tam engelli düzen için güç sayısının Reynolds sayısı ile değişimi

Şekil 5'te bütün düzenlerde, yani tam engel, tabandan boşluklu engel, yarım engel, yüzey engeli ve engelsiz düzenlerde değişen Reynolds sayılarında elde edilen güç sayıları verilmiştir. Görüldüğü üzere bütün engel tiplerinde ve engelsiz düzende güç sayıs1-Reynolds sayıs1 eğrisi tam engel düzeninde elde edilen ile benzer özellikleri taşımakta, şekil olarak onunla uyum göstermektedir. Bu durum, bu verilerin aynı zamanda eğilim açısından engelli tanklardaki literatür verileri ile uyumlu olduğunu göstermektedir.

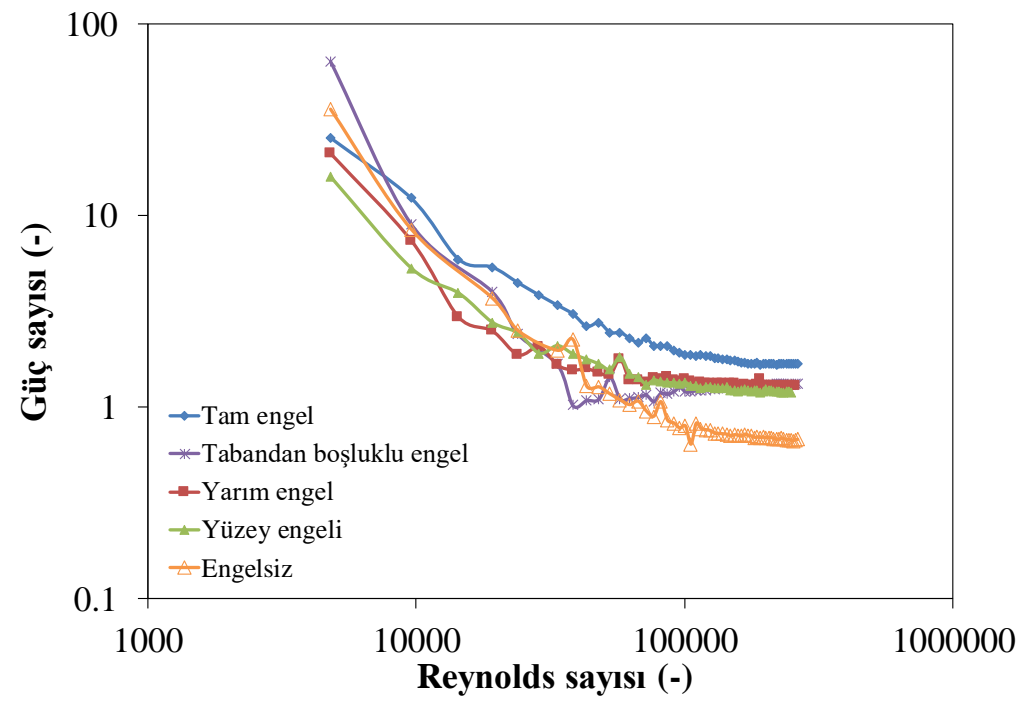

Şekil 5. Farklı engel düzenlerinde güç sayısının Reynolds sayısı ile değişimi 
Bütün düzenlerde, test edilen en düşük Reynolds sayıs1 olan 4780 geçiş rejimini temsil etmektedir. Bu akış rejiminde Şekil 5'te görüldügü üzere engel yüzeyden yarıma ve yarımdan tam engele doğru uzatıldığında güç sayısı \%18-25 arası artma göstermiştir. Buradan, engel tankın içerisinde yüzeyden aşağı doğru uzatıldıkça güç sayısının arttığı sonucu çıkarılabilir. Ancak tabandan boşluklu engel kullanıldığında en düşük Reynolds sayısında güç sayısı, tam engel düzenindeki değerini de geçmektedir. Güç sayısı tam engel değerinden \%149 daha fazladır. Engelsiz düzende ise bu artış \%40 oranındadır. $\mathrm{Bu}$, eğer tank geçiş rejiminde işletilecek ise tabandan boşluklu engelin veya engelsiz düzenin kullanılmasının diğer engel tasarımlarına göre çok daha fazla güç tüketimine sebep olacağını göstermektedir. Geçiş rejiminde işletim her türlü geometride ve süreçte zorludur. Burada da benzer bir durum görülmektedir. Bu sebeple elde edilen sonuçlara göre geçiş rejiminde tabandan boşluklu engel ve engelsiz düzenlerin kullanılması tavsiye edilmemektedir.

Endüstriyel süreçlerin pek çoğu türbülent rejimde çalıştırılmaktadır. Tam türbülent rejimde tam engelli tanklarda güç sayısı Reynolds sayısı ile bir değişim göstermez. Şekil 6, bu durumun bu çalışmada incelenen farklı engel düzenleri için de geçerli olduğunu göstermiştir. Güç sayısının sabit olması güç tüketiminin hesabını kolaylaştırır. Şekil 6'da tam türbülent koşullarda, yani Reynolds sayısının 200 000'den fazla olduğu durumda güç sayısının farklı düzenlerdeki değerleri gösterilmiştir. Belli bir Reynolds sayısı aralığına odaklanılması farklı düzenlerdeki güç sayılarının daha açık bir şekilde görülmesini de sağlamaktadır. Her bir düzen için sabit güç sayısı değerleri Tablo 2'de verilmiştir. Şekil 6'da açıç̧a görüldüğü üzere değişen Reynolds sayılarında güç sayısı hemen hemen değişmemekte, sadece belli bir ortalama değer etrafında küçük artış ve azalışlar göstermektedir. Raporlanan güç sayısı değerleri şekilde verilen Reynolds sayısı aralığında elde edilen güç sayılarının ortalama değeridir. Türbülent güç sayısı, tam engelden tabandan boşluklu engele geçildiğinde $\% 22$, tabandan boşluklu engelden yarım engele geçildiğinde $\% 2.3$, yarım engelden yüzey engeline geçildiğinde $\% 5.5$ ve yüzey engelinden engelsiz düzene geçildiğinde \%44 azalmaktadır. Engelin tank içerisinde varlığı azaldıkça türbülent güç sayısı da azalmaktadır. Engeller tanktaki akışın yönünü değiştirmekte, bu sebeple de güç tüketimine sebep olmaktadır. Bu sebeple tankın içindeki engel varlığı azaldıkça güç sayısının da düşmesi anlamlıdır. Daha önce Şekil 5 'te geçiş rejiminde tabandan boşluklu engel ve engelsiz düzenlerde görülen tam engel düzeninden de yüksek güç sayıları tam türbülent rejimde artık görülmemektedir.

Tablo 2. Bütün engel düzenleri için türbülent güç sayısı

\begin{tabular}{|l|c|}
\hline Engel düzeni & Güç sayısı \\
\hline Tam engel & 1,68 \\
\hline Tabandan boşluklu engel & 1,31 \\
\hline Yarım engel & 1,28 \\
\hline Yüzey engeli & 1,21 \\
\hline Engelsiz & 0,67 \\
\hline
\end{tabular}

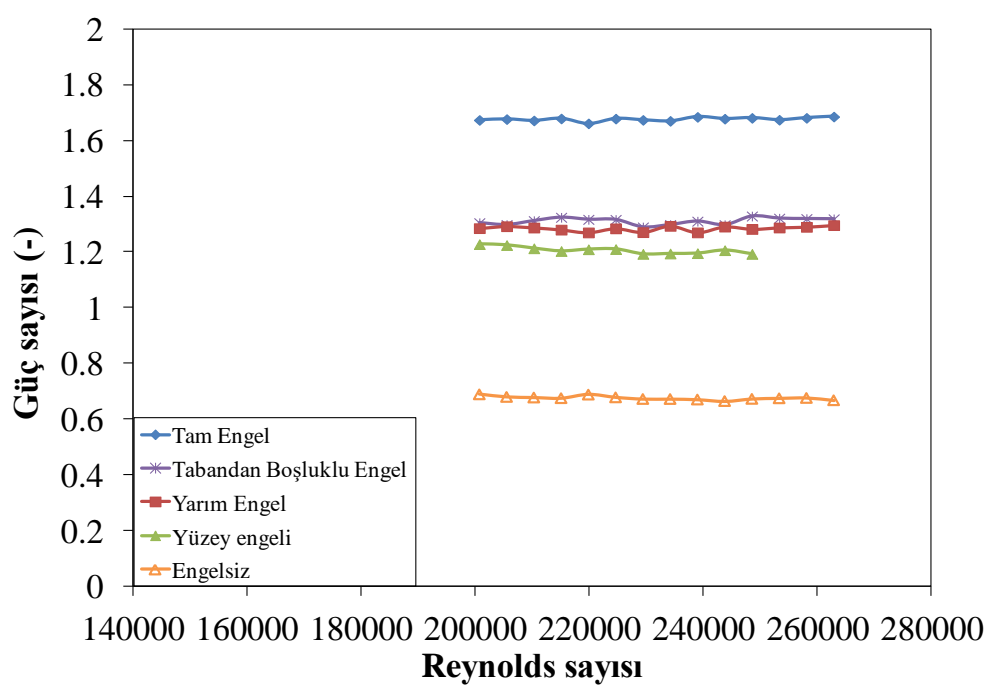

Şekil 6. Farklı engel düzenlerinde türbülent güç sayısının Reynolds sayısı ile değişimi 
Farklı engel düzenlerindeki güç sayılarının bilinmesi ile tasarım aşamasında güç sayısı hesabı yapılması mümkün olur. Böylelikle hem gerekli motor seçimi yapılabilir hem de engel düzenleri arasında bir seçim yapılabilir. Şekil 7 böyle bir tasarım durumu için örnek güç tüketimi hesaplarının sonuçlarını göstermektedir. 1m çapındaki bir karıştırmalı tankın türbülent rejimde çalıştırılacağı varsayılmıştır. Sıvı faz olarak su öngörülmüştür. Akış rejiminden dolayı Şekil 6'da görülen ve Tablo 2'de sıralanan türbülent güç sayılarının kullanılması gerekmektedir. Bu güç sayıları Eşitlik 1'de yerine konulmuş ve farklı karıştrıcı hızları için güç tüketimleri hesaplanmıştır. Şekil 7'de görüldügü üzere en yüksek güç tüketimi tam engelin olduğu durumda, en düşük güç tüketimi ise engelsiz durumda elde edilmiştir. Diğer engel düzenlerinde güç tüketimi tam engelden daha düşük, ancak engelsiz düzenden oldukça yüksektir. Fark, yüksek karıştırıcı hızlarında daha belirgin hale gelmektedir. Bu durumda tabandan boşluklu, yarım ve yüzey engelleri arasında bir seçim yapılması gerekirse karar güç tüketiminden bağımsız, sadece akış yönleri ve sürecin gerektirdikleri baz alınarak yapılabilir. Bu engel düzenlerinden birine karar verildiğinde ise bu makalede verilen güç sayıları kullanılarak işletimin yapılacağı karıştırıcı hızlarına karşılık gelen güç değerleri ve sonrasında da tork değerleri hesaplanabilir. Bu tork değerleri ile de kullanılacak motorun seçimi gerçekleştirilebilir.

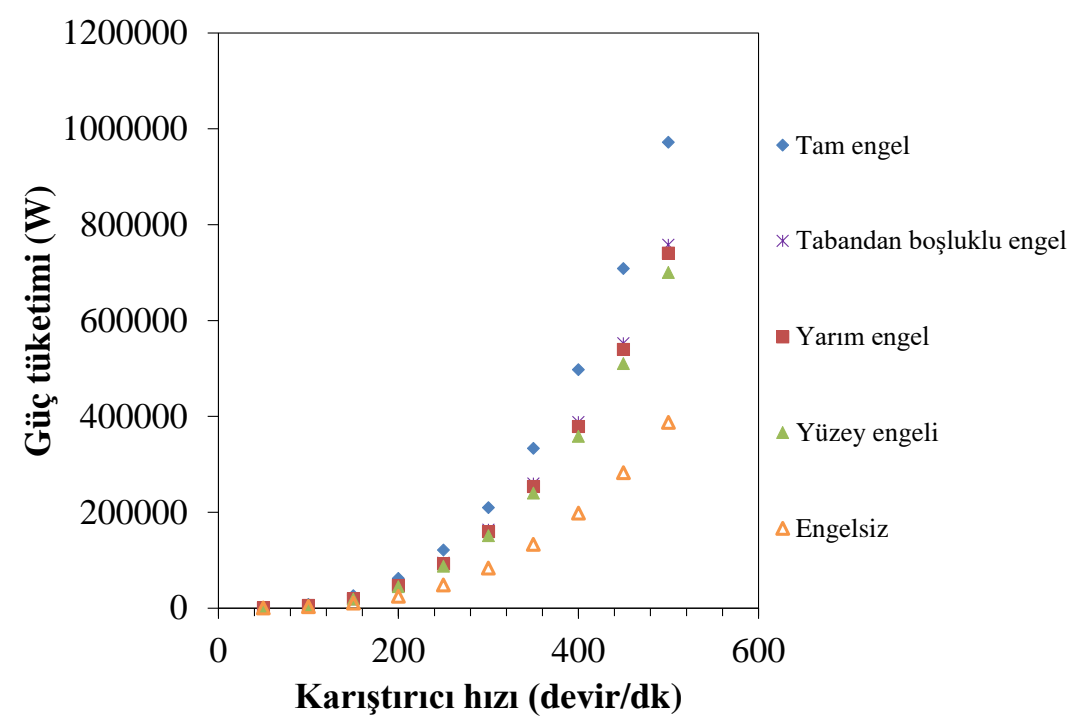

Şekil 7. Farklı engel düzenlerinde $1 \mathrm{~m}$ çapındaki bir karıştırmalı tank için hesaplanan güç tüketimleri

\section{Sonuç ve Öneriler}

Bu çalışmada PBT karıştırıcı ile karıştırılan bir tankta farklı engel tipleri kullanıldığında karıştırıcı güç sayısının nasıl değiştiği incelenmiş ve bu farklı düzenler için türbülent güç sayısı rapor edilmiştir. Elde edilen önemli sonuçlar şu şekildedir:

- Test edilen dört engel uzunluğunda ve engelsiz düzende elde edilen güç sayısı-Reynolds sayısı grafikleri birbiri ile benzer eğilimler göstermiştir. $\mathrm{Bu}$ eğilimler standart olarak tam engel için sunulan literatür verileri ile de uyumludur.

- Geçiş rejiminde tabandan boşluklu engel ve engelsiz düzenlerde güç sayıları diğer düzenlere göre çok daha yüksek çıkmıştır. Belli bir süreç tasarımında geçiş rejiminde çalışılacak ise bu iki düzenden kaçınılması tavsiye edilmektedir. Bir başka engel uzunluğu seçilerek güç tüketimi ciddi oranda düşürülebilecektir.

- Türbülent güç sayıları karşılaştırıldığında engelin tank içerisindeki varlığı azaldıkça güç sayısının da büyük oranda azaldığ 1 görülmüştür. PBT karıştırıcı için tam, tabandan boşluklu, yarım, yüzey engeli ve engelsiz düzenlerde türbülent güç sayıları sırası ile 1,68, 1,31, 1,28, 1,21 ve 0,67 olarak bulunmuştur. Bir süreç için tank tasarımı yapılırken bu güç sayısı değerleri kullanarak güç tüketimi hesabı yapılabilir ve bu şekilde hem süreç amaçlarını karşılayacak hem de enerji tüketimini minimize edecek en uygun geometrik düzen seçilebilir. 


\section{Teşekkür}

TÜBİTAK'a destekleri için teşekkür ederiz (Proje no: 117M158).

\section{Yazarların Katkısı}

Makalenin fikri, veri analizi, grafik ve görsellerin oluşturulması, makale yazımı İnci AYRANCI’ya aittir. Veriler Gökhan GÖK tarafından alınmıştır.

\section{Çıkar Çatışması Beyanı}

Yazarlar arasında herhangi bir çıkar çatışması bulunmamaktadır.

\section{Araştırma ve Yayın Etiği Beyanı}

Yapılan çalışmada araştırma ve yayın etiğine uyulmuştur.

\section{Kaynaklar}

[1] Hemrajani R.R., Tatterson G.B. 2004. Mechanically stirred vessels in Handbook of Industrial Mixing: Science and Practice. John Wiley\&Sons, New Jersey.

[2] Ayranci I., Machado M.B., Madej A.M., Derksen J.J., Nobes D.S., Kresta S.M. 2012. Effect of geometry on the mechanisms for off-bottom solids suspension in a stirred tank. Chemical Engineering Science, 79: 163-176.

[3] Assirelli M., Bujalski W., Eaglesham A., Nienow A.W. 2008. Macro- and micromixing studies in an unbaffled vessel agitated by a Rushton turbine. Chemical Engineering Science, 63: 35-46.

[4] Myers K.J., Fasano J.B. 2002. The influence of baffle off-bottom clearance on the solids suspension performance of pitched blade and high-efficiency impellers. Canadian Journal of Chemical Engineering, 70: 596-599.

[5] Khazam O., Kresta S.M. 2009. A novel geometry for solids drawdown in stirred tanks. Chemical Engineering Research \& Design, 87 (3A): 280-290.

[6] Bates R.L., Fondy P.L., Corpstein R.R. 1963. An examination of some geometric parameters of impeller power. Industrial \& Engineering Chemistry Research, 2 (4): 310-314.

[7] Yianneskis M., Popiolek Z., Whitelaw J.H. 1987. An experimental study of the steady and unsteady-flow characteristics of stirred reactors. Journal of Fluid Mechanics, 175: 537-555.

[8] Ibrahim S., Nienow A.W. 1995. Power curves and flow patterns for a range of impellers in Newtonian fluids: $40<\operatorname{Re}<5 \times 10^{5}$. Chemical Engineering Research\&Design, 73 (A5): 485-491.

[9] Armenante P.M., Mazzarotta B., Chang G.M. 1999. Power consumption in stirred tanks provided with multiple pitched-blade turbines. Industrial \& Engineering Chemistry Research, 38 (7): 28092816.

[10] Rutherford K., Mahmoudi S.M.S., Lee K.C., Yianneskis M. 1996. The influence of Rushton impeller blade and disk thickness on the mixing characteristics of stirred vessels. Transactions of the Institution of Chemical Engineers, 74 (A3): 369-378.

[11] Rushton J.H., Costich E.W., Everett H.J. 1950. Power characteristics of mixing impellers. Chemical Engineering Progress, 46 (8): 395-476.

[12] Nagata S. 1975. Mixing: Principles and Applications. John Wiley \& Sons, New York.

[13] Chapple D., Kresta S.M., Wall A., Afacan A. 2002. The effect of impeller and tank geometry on power number for a pitched blade türbine. Transactions of the Institution of Chemical Engineers, 80 (A): 364-372.

[14] Machado M.B., Bittorf K.J., Vesselina T.R., Kresta S.M. 2013. Transition from turbulent to transitional flow in the top half of a stirred tank. Chemical Engineering Science, 98: 218-230. 